\title{
Pharmacological Manipulation of Cortical Inhibition in the Dorsolateral Prefrontal Cortex
}

\author{
Bahar Salavati ${ }^{1,2,3,4}$, Tarek K Rajji 1,2,3,4, Reza Zomorrodi ${ }^{1,2,3,4}$, Daniel M Blumberger ${ }^{1,2,3,4}$, Robert Chen ${ }^{5}$, \\ Bruce G Pollock ${ }^{1,2,3}$ and Zafiris J Daskalakis*,1,2,3,4 \\ ' Centre for Addiction and Mental Health, Toronto, Canada; ${ }^{2}$ Department of Psychiatry, University of Toronto, Toronto, Canada; ${ }^{3}$ Campbell Family \\ Mental Health Research Institute, Centre for Addiction and Mental Health, Toronto, Canada; ${ }^{4}$ Department of Psychiatry, Temerty Centre for \\ Therapeutic Brain Intervention, Centre for Addiction and Mental Health, Toronto, Canada; ${ }^{5}$ Division of Neurology, Department of Medicine, \\ University Health Network and University of Toronto, Toronto, Canada
}

\begin{abstract}
Cortical inhibition $(\mathrm{Cl})$ occurs largely through GABA receptor-mediated inhibitory neurotransmission, which can be modulated by cholinergic, dopaminergic, and glutamatergic inputs. Transcranial magnetic stimulation (TMS) can be used to index $\mathrm{Cl}$ through a paradigm known as long-interval Cl (LICl). When TMS is combined with electroencephalography (EEG), $\mathrm{LICl}$ can index GABA receptor-mediated inhibitory neurotransmission in the dorsolateral prefrontal cortex (DLPFC). We conducted a hypothesis-driven pharmacological study to assess the role of cholinergic, dopaminergic, GABAergic, and glutamatergic neurotransmission on LICl from the DLPFC using TMS-EEG. In this randomized controlled, double-blind crossover within-subject study, 12 healthy participants received five sessions of LICI to the DLPFC in a random order, each preceded by the administration of placebo or one of the four active drugs. $\mathrm{LICl}$ was assessed after each drug administration and compared to $\mathrm{LICl}$ after placebo. Relative to placebo, baclofen resulted in a significant increase in $\mathrm{LICl}$, while rivastigmine resulted in a significant decrease in $\mathrm{LICl}$. Dextromethorphan and L-DOPA did not result in a significant change in $\mathrm{LICl}$ relative to placebo. Our study confirms that $\mathrm{LICl}$ in the DLPFC is largely mediated by GABA receptor-mediated inhibitory neurotransmission and also suggests that cholinergic modulation decreases LICI in the DLPFC. Such findings may help guide future work examining the neurophysiological impact of these neurotransmitters in healthy and diseased states.

Neuropsychopharmacology (2018) 43, 354-36I; doi:I0.1038/npp.2017.104; published online 21 June 2017
\end{abstract}

\section{INTRODUCTION}

The dorsolateral prefrontal cortex (DLPFC) is a critical brain region that is involved in several important domains of cognition including learning and memory (Fuster, 2008). Abnormalities in DLPFC structure and function are observed in various brain disorders including addiction (Naim-Feil et al, 2015), Alzheimer's disease (Kaufman et al, 2010), depression (Koenigs and Grafman, 2009), Parkinson's disease (Ko et al, 2013), and schizophrenia (Goto et al, 2010). GABA plays an important role in DLPFC function as it synchronizes the activity of pyramidal neurons (Sederberg et al, 2007). This synchronization is closely related to GABA receptor function and shown to play a role in learning and memory (Heaney and Kinney, 2016). Thus, studying the mechanisms involved in GABA receptor-mediated inhibitory neurotransmission from the DLPFC could advance our

*Correspondence: Dr ZJ Daskalakis, Department of Psychiatry, Temerty Chair in Therapeutic Brain Intervention, Chief, Mood and Anxiety, University of Toronto, Centre for Addiction and Mental Health $(\mathrm{CAMH}), 1001$ Queen Street West, Unit 4-I, Toronto, Ontario, Canada M6J IH4, Tel: +4I6 535-850 I, ex: 34319, Fax: +4I6 5956728 , E-mail: Jeff.Daskalakis@camh.ca

Received 15 January 2017; revised 3 May 2017; accepted 22 May 2017; accepted article preview online 29 May 2017 knowledge of the mechanisms involved in cognition while also helping to identify treatment for disorders in which the DLPFC has been shown to be dysfunctional (eg, depression, schizophrenia).

Transcranial magnetic stimulation (TMS) combined with electroencephalography (EEG) can be used to assess in vivo GABA neurotransmission from the DLFPC through a paradigm known as long-interval cortical inhibition (LICI) with high test-retest reliability (Farzan et al, 2010). LICI is a paired pulse inhibitory paradigm that consists of a suprathreshold conditioning stimulus (CS), followed by a suprathreshold test stimulus at a long interstimulus intervals (eg, 50-200 ms) (Valls-Sole et al, 1992).

There are several lines of evidence that suggest that LICI reflects $\mathrm{GABA}_{\mathrm{B}}$ receptor-mediated inhibitory neurotransmission. First, LICI reduces short interval CI (SICI), a GABA receptor-mediated inhibitory paradigm (Sanger et al, 2001). This is consistent with the finding that presynaptic $\mathrm{GABA}_{\mathrm{B}}$ activation inhibits GABA release with a concomitant reduction in $\mathrm{GABA}_{\mathrm{A}}$ receptor-mediated inhibition (Werhahn et al, 1999). Second, LICI is evoked with a suprathreshold intensity CS, which produces a long lasting inhibition (Valls-Sole et al, 1992) supporting the finding that $\mathrm{GABA}_{\mathrm{B}}$ receptor-mediated inhibition has a greater activation threshold and longer inhibitory effect that peaks at around 
135 ms (McCormick, 1989; Sanger et al, 2001). Third, the administration of $\mathrm{GABA}_{\mathrm{B}}$ receptor agonist baclofen has been shown to enhance LICI (McDonnell et al, 2006). Furthermore, LICI has been linked to DLPFC function, as prefrontal LICI strength correlates with individual performance on a working memory task (Rogasch et al, 2015) and found to be dysfunctional in disorders including schizophrenia (Radhu et al, 2015) Parkinson's (Chu et al, 2009), and depression (Croarkin et al, 2014).

Although LICI is closely linked to $\mathrm{GABA}_{\mathrm{B}}$ receptormediated inhibitory neurotransmission, the influence of other neurotransmitters cannot be excluded. The interaction between GABAergic with dopaminergic, cholinergic, and glutamatergic neurotransmission is complex. Dopamine facilitates GABA release via dopamine $D_{1}$ receptors and inhibits release via dopamine $\mathrm{D}_{2}$ receptors (Harsing and Zigmond, 1997). GABAergic activity is also enhanced through cholinergic nicotinic receptors or muscarinic $M_{3}$ receptors but inhibited through muscarinic $\mathrm{M}_{4}$ receptors (Zhang and Warren, 2002). Finally, NMDA activation on GABAergic neurons enhances GABAergic activity, while NMDA antagonism on glutamatergic neurons reduces excitatory drive on GABAergic neurons resulting in decreased inhibition in the cortex (Olney et al, 1999).

The application of a single dose of a central nervous system (CNS) drug that acts on a specific neurotransmitter or neuromodulator system has been used to understand TMS measures of CI and excitation. For instance, CNS drugs, such as baclofen, and dextromethorphan have been used to increase and decrease GABAergic and glutamatergic tone, respectively, while rivastigmine and L-DOPA have been used to increase cholinergic and dopaminergic tone, respectively.

Several studies suggest that in vivo LICI from the motor cortex in healthy controls is enhanced by increasing GABAergic tone, as GABAergic drugs such as, baclofen (McDonnell et al, 2006; Premoli et al, 2014) vigabatrin (Pierantozzi et al, 2004), and tiagabine (Werhahn et al, 1999) increased LICI, tiagabine possibly through $\mathrm{GABA}_{\mathrm{B}}$ activation due to the increased availability of GABA in the synaptic cleft (Ziemann et al, 2015). Nonetheless, the contribution of other neurotransmitters on LICI is unknown (Paulus et al, 2008). A few studies have assessed the pharmacological modulation of these neurotransmitters on in vivo cortical excitability in the motor cortex. Both dextromethorphan and L-DOPA decreased cortical excitability (Priori et al, 1994; Ziemann et al, 1998a), while rivastigmine had no significant effect

Table I Properties of Drugs Used in the Study

\begin{tabular}{llcc}
\hline Drugs & $\begin{array}{l}\text { Main mechanism of } \\
\text { action }\end{array}$ & $\begin{array}{c}\text { Dose } \\
(\mathbf{m g})\end{array}$ & $\begin{array}{c}\text { Plasma peak } \\
\mathbf{( h )}\end{array}$ \\
\hline Baclofen & GABA-B agonist & 50 & 1 \\
Dextromethorphan & NMDA antagonist & 150 & 3 \\
L-DOPA & Dopamine precursor & 100 & 1 \\
Rivastigmine & $\begin{array}{l}\text { Acetylcholine-esterase } \\
\text { inhibitor }\end{array}$ & 3 & 2 \\
Placebo & - & - & I, 2, or 3a \\
\hline
\end{tabular}

aPlacebo was randomly given to each participant at I, 2, or $3 \mathrm{~h}$ prior to the administration of post-LICl.
(Langguth et al, 2007). One limitation of these findings is that TMS was applied to the motor cortex as opposed to the DLPFC, the latter being a cortical region whose physiological function is of considerable significance in attempting to understand the pathophysiology of severe psychiatric disorders.

To date, no study has assessed the pharmacological modulation of LICI from DLPFC stimulation. Further, no study has assessed all of these drugs in the same participants using a double-blind randomized controlled design. Thus, we conducted the first pharmacological modulation of DLPFC LICI in vivo using TMS-EEG and a double-blind, randomized controlled within-subject design that included all of the above four drugs. We hypothesized that, compared to placebo, baclofen, L-DOPA, and dextromethorphan and would increase LICI, while rivastigmine would decrease it.

\section{MATERIALS AND METHODS}

\section{Overall Study Design}

This was a double-blinded randomized controlled withinsubject crossover study. Each participant received five sessions of LICI in a random order, each preceded by the administration of a placebo or one of the four active drugs, and separated by at least 1 week to minimize drug interference and carryover effects (Korchounov and Ziemann, 2011). LICI was measured pre-drug and post-drug, and post-LICI was administered after the drug had reached plasma peak level (Table 1). The doses of the drugs were based on the previous studies demonstrating effects at similar doses on LICI in the motor cortex. Across the subjects, the sequences of drug administration were counterbalanced. The administrator of the experiments and participants were blind to drug assignment. All data processing and analyses were also completed under blind condition.

\section{Participants}

Participants were four females and nine males; average age 31.3 (10.5) years; not diagnosed with any medical problems; non-smokers, negative for urine toxicology screen for drugs of abuse; right-handed to ensure homogeneity in hemisphere dominance; had no contraindication to TMS (Rossi et al, 2009) or MRI; and provided written informed consent. The study was conducted in accordance with ethical standards of the responsible committee on human experimentation and approved by the Centre for Addiction and Mental Health Research Ethics Board. Thirteen participants (four females and nine males) took part in this study. All participants completed all sessions except for one participant who dropped out after only one of the five sessions and data for this participant was not used. Participants' demographics and basic neurophysiologic characteristics are described in Table 2 .

\section{Locating and Co-Registering the DLPFC}

The left DLPFC is located at the junction of the middle and anterior third of the middle frontal gyrus (Talairach coordinates $(x, y, z)=(-50,30,36))$, which corresponds to the posterior region of Brodmann area 9 and the superior section 
Table 2 Demographic and Basic Neurophysiologic Characteristics

\begin{tabular}{lc}
\hline Characteristic & Mean (SD) \\
\hline Age (years) & $31.3($ I 0.5) \\
Gender (female, \%) & $4(25)$ \\
Education (years) & $15.3(2.3)$ \\
RMT (\% stimulator output) & $49.0(0.74)$ \\
SIImV (\% stimulator output) & $61.7(1.5)$ \\
\hline
\end{tabular}

Abbreviations: MEP, motor-evoked potential; RMT, resting motor threshold.

${ }^{a} \mathrm{SII} \mathrm{mV}=$ Stimulation intensity with a mean peak-to-peak MEP amplitude of I $\mathrm{mV}$ over 20 trials

of area 46 (Rusjan et al, 2010). Following previously published methods the localization of the DLPFC was achieved through neuronavigation techniques using the MINIBIRD system (Ascension Technologies) and each participant's T1-weighted MRI with seven fiducial markers placed on the nasion, inion, left and right tragus, and vertex (Daskalakis et al, 2008).

\section{TMS-EMG in the Motor Cortex and TMS-EEG in the DLPFC}

Following established methods (Daskalakis et al, 2008) (Sun et al, 2016) we used a $7 \mathrm{~cm}$ figure-eight coil and a Magstim 200 stimulator (The Magstim Company, Whitland, UK) to determine the participant's resting motor threshold (RMT) (defined as the minimum stimulus intensity that elicits a motor-evoked potential (MEP) of more than $50 \mathrm{mV}$ in five of ten trials) from the left motor cortex. MEP activity was measured through EMG recordings from the right abductor pollicis brevis muscle. The RMT stimulus intensity was then adjusted to a suprathreshold intensity with mean peak-topeak MEP amplitude of $\sim 1 \mathrm{mV}$ over 20 trials, which corresponded to $\sim 120 \%$ of the RMT. This intensity, referred to as SI1 $\mathrm{mV}$ was then used to deliver 100 single-TMS pulses (test pulse only) and 100 paired (condition pulse followed $100 \mathrm{~ms}$ by a test pulse (LICI 100)) with an interstimulus of $5 \mathrm{~s}$ between each of the pulses to the scalp over the left DLPFC, pre-drug and then again post-drug, to assess change. To ensure identical placement throughout the experiment the location of the left DLPFC was marked on the EEG cap with a marker. When stimulating the left DLPFC the handle of the TMS coil was pointed backwards, at $\sim 45^{\circ}$ to the midsagittal line.

To evaluate TMS-induced cortical-evoked potentials, we used a 64-channel Synamps 2 EEG system. All electrodes $(\mathrm{Ag} / \mathrm{AgCl}$ ring electrodes) impedance were $\leq 5 \mathrm{k} \Omega$ and referenced to an electrode positioned posterior to $\mathrm{Cz}$ electrode. In addition, EEG signals were recorded using DC and a lowpass filter, antialiasing filter, of $200 \mathrm{~Hz}$, at $20 \mathrm{kHz}$ sampling rate, which has been shown to avoid saturation of amplifiers and to minimize TMS-related artifact (Sun et al, 2016).

\section{EEG Data Processing}

All analysis was done while blinded and we were only unblinded once the data was finalized. EEG data was analyzed using MATLAB (The MathWorks Natick, MA, USA) and a custom script that was developed based on previous work (Sun et al, 2016). The recorded EEG data for both single pulse and paired pulse were first downsampled from 20 to $1 \mathrm{kHz}$ and then segmented into epochs from -1000 to $+2000 \mathrm{~ms}$ after the test TMS stimulus. Each trial was then baseline corrected with the mean of the TMS artifact-free time period $(-500$ to $-110 \mathrm{~ms})$ before the test stimulus onset. To remove the TMS artifact, the EEG data was segmented from $25 \mathrm{~ms}$ before the onset of each TMS pulse until $2000 \mathrm{~ms}$ after the onset and this section was used for further analysis. Thereafter, the EEG data was digitally filtered using a second-order, Butterworth, zero-phase shift $1-55 \mathrm{~Hz}$ band pass filter (24 dB/Oct). EEG recordings from Pre-LICI and Post-LICI were then concatenated in order to apply the same objective criteria for de-noising the data. Then, an electrodes-by-trials matrix of ones and zeros was created and assigned a value of zero if an epoch had the following: (1) amplitude larger than $\pm 150 \mu \mathrm{V}$; (2) power spectrum that violated 1/f power law; or (3) SD three times larger than the average of all trials. An electrode was rejected if its corresponding row had more than $60 \%$ of columns (trials) coded as zeros. An epoch was removed if its corresponding column had more than $20 \%$ of rows (electrodes) coded as zeros (Sun et al, 2016). Next, independent component analysis (EEGLAB toolbox; Infomax algorithm) was performed to remove remaining artifacts such as eyeblink traces, muscle artifacts from the EEG data (Sun et al, 2016). Finally, the data was re-referenced to the average, generating a clean signal devoid of noise for each participant.

\section{LICI Quantification}

The modulating effects of the drugs on LICI were calculated by the following steps: (I) determining the cortical-evoked activity (CEA) by averaging 100 single pulses, and 100 paired pulses which were then rectified. (II) For the paired pulse, the CEA from the single pulse condition (test pulse) was shifted $100 \mathrm{~ms}$ and aligned with the conditioning pulse of the paired pulse CEA and subtracted resulting in a corrected paired pulse. This approach has been shown to be a more accurate measure of the paired pulse CEA as it removes the rippling effect of the conditioning stimuli, and has been used in other similar studies (Sun et al, 2016) (Premoli et al, 2014). (III) After correcting the paired pulse, LICI was calculated based on equation provided in manuscript (Figure 1), which divides the area under the rectified curve of the CEA waveform for the corrected paired pulse by the area under the rectified curve of the CEA waveform for the single pulse. The area of interest was from 50 to $275 \mathrm{~ms}$ in accordance with previously published work (Sun et al, 2016). To capture the effects of LICI from the frontal brain region, the average value from the following frontal electrodes were used: FP1, FPZ, FP2, AF3, AF4, F7, F5, F3, F1, FZ, F2, F4, F6, and F8. These frontal electrodes were selected for two main reasons. First, these electrodes are the least influenced by muscle activity and TMS-related artifacts. Second, frontal electrodes show the greatest and most consistent inhibitory response from DLPFC stimulation (Sun et al, 2016). 


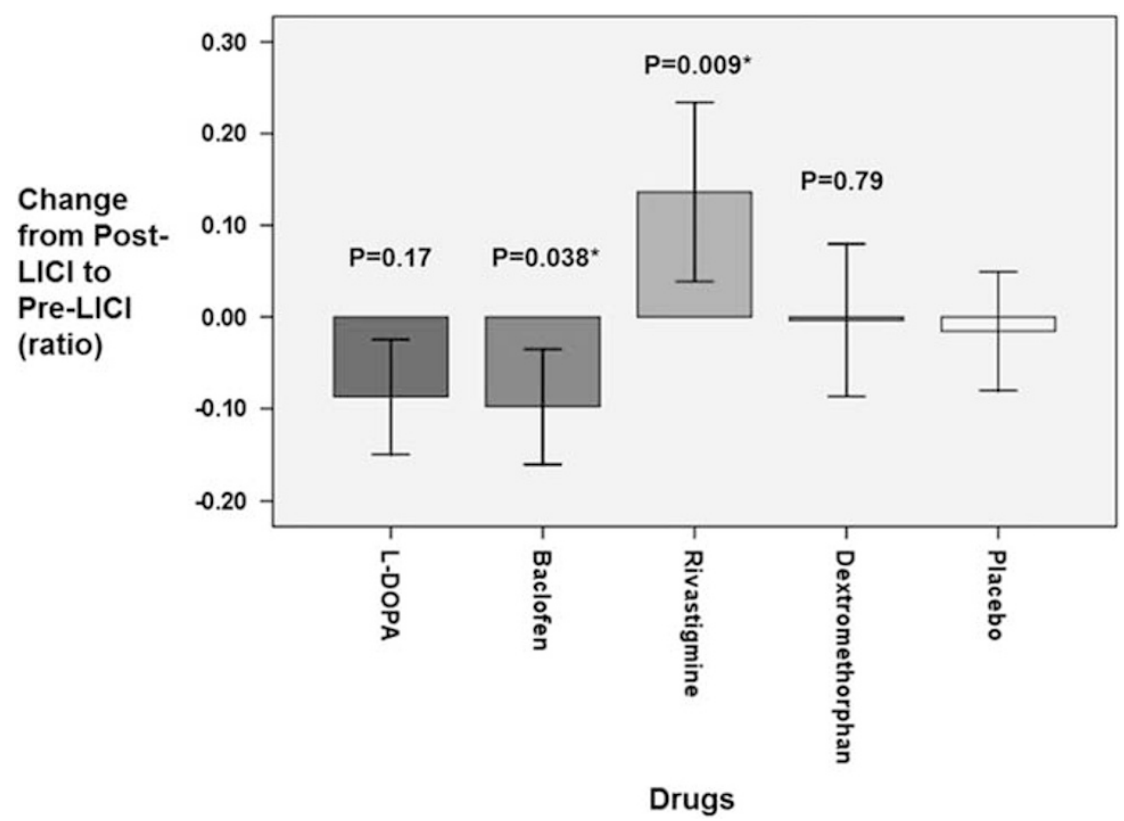

Figure I Effects of drugs on DLPFC LICl. This figure illustrates the effects of drugs (L-DOPA, baclofen, rivastigmine, dextromethorphan, and placebo) on DLPFC LICl expressed as a change of post-LICl from pre-LICI CEA. The p-values refer to the comparisons between each active drug and placebo. Error bars: +/ - ISE.

\section{Statistical Analysis}

All data was first checked for normality using the Kolmogorov-Smirnov test. To test our primary hypotheses and assess whether there is a drug effect on LICI, a repeated measures analysis of variance (rmANOVA) was conducted with the drug condition (placebo vs baclofen vs dextromethorphan vs L-DOPA vs rivastigmine) as the repeated measure. This was followed by a series of post hoc analyses, to compare LICI under each of the active drug conditions to LICI under placebo.

\section{RESULTS}

All outcome data were normally distributed. rmANOVA revealed that there was a drug effect on $\operatorname{LICI}(\mathrm{F}(4,44)=6.34$, $p<0.001)$. Further, post hoc pairwise comparisons against placebo revealed that LICI was decreased after the intake of rivastigmine $(p=0.009)$ and increased after baclofen $(p=0.038)$. In contrast, there was no significant change after the intake of L-DOPA $(p=0.17)$ or dextromethorphan $(p=0.79)$ when compared with placebo. (Figure 1). The topography of all DLPFC LICI values across all electrodes is shown in Figure 2.

Finally, from pre-LICI to post-LICI, participants showed a significant difference under L-DOPA, rivastigmine, and baclofen but not for dextromethorphan condition (Table 3).

\section{DISCUSSION}

This study confirmed our hypotheses that baclofen enhances and rivastigmine decreases LICI from the DLPFC in vivo. It did not confirm our hypotheses that dextromethorphan and L-DOPA decrease LICI compared to placebo. To our knowledge, this is the first study to assess the pharmacological modulation of LICI from DLPFC stimulation in humans.

As hypothesized we found that baclofen enhanced LICI compared to placebo. Baclofen is a $\mathrm{GABA}_{\mathrm{B}}$ receptor agonist (Faigle and Keberle, 1972) that increases inhibition through the allosteric modulation of $\mathrm{GABA}_{\mathrm{B}}$ receptor-mediated neurotransmission (Mann-Metzer and Yarom, 2002). This finding is consistent with animal studies that showed baclofen enhanced inhibition in the cortex (Porter and Nieves, 2004). Our result also replicates and extends to TMS human studies that assessed the effect of baclofen on LICI in the motor cortex (McDonnell et al, 2006; Premoli et al, 2014).

Furthermore, in disorders where LICI has been shown to be dysfunctional (eg, schizophrenia, (Radhu et al, 2015), Parkinson's (Chu et al, 2009), and depression (Croarkin et al, 2014), these findings suggest that drugs targeting the $G_{A B A}$ receptor may reverse these deficits and even have a therapeutic role. As an example, clozapine, which is one of the most effective treatments for schizophrenia, has been shown to increase $\mathrm{GABA}_{\mathrm{B}}$ receptor-mediated neurotransmission (Kaster et al, 2015). These results, therefore, also suggest that measuring LICI in the DLPFC may be a possible treatment or biomarker for schizophrenia.

We also found that rivastigmine reduces LICI from DLPFC stimulation. To the best of our knowledge, no study has examined the effects of rivastigmine on LICI. One study, however, assessed the effects of rivastigmine on cortical excitability from the human motor cortex and reported an enhancement of MEP amplitude after a single dose (Langguth et al, 2007), which supports our finding given that enhanced MEP indicates reduced CI (Bestmann and Krakauer, 2015). These findings are also consistent with animal studies that reported increased cortical excitation in the prefrontal cortex following cholinergic intervention 

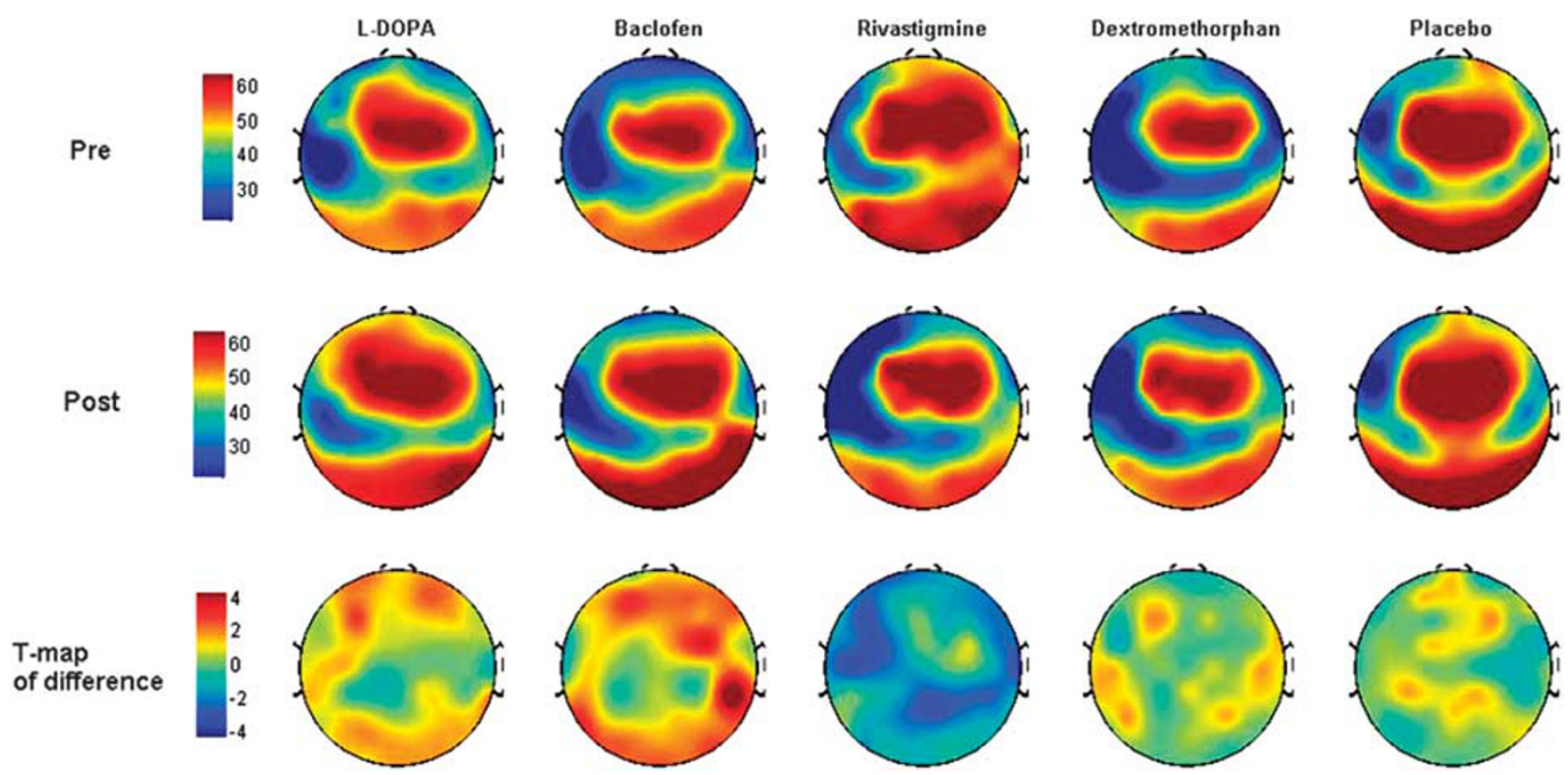

Figure 2 Topographical plots of $\mathrm{LICl}$. These topographical plots illustrate the effects of drugs (L-DOPA, baclofen, rivastigmine, dextromethorphan (DMO), and placebo) on inhibition from DLPFC stimulation. Rivastigmine significantly decreased and baclofen increased inhibition compared to placebo, while L-DOPA and dextromethorphan did not. Increased inhibition is shown as more red, while decreased inhibition is shown as more blue. LICl from DLPFC stimulation is most prominent at frontal locations when plotted topographically across all electrodes.

Table 3 Pre-Drug vs Post-Drug LICl from Stimulation to Dorsolateral Prefrontal Cortex Under each Drug Condition

\begin{tabular}{lcccc}
\hline Drug & $\begin{array}{c}\text { Pre-Drug } \\
\text { LICl }\end{array}$ & $\begin{array}{c}\text { Post-Drug } \\
\text { LICl }\end{array}$ & $\boldsymbol{t}$ (df) & p-value \\
\hline Placebo & $0.52(0.14)$ & $0.51(1.0)$ & $0.48(1 \mathrm{I})$ & 0.64 \\
Baclofen & $0.63(0.19)$ & $0.53(0.17)$ & $3.14(1 \mathrm{I})$ & $0.009 *$ \\
Dextromethorphan & $0.62(0.13)$ & $0.62(0.23)$ & $0.85(\mathrm{II})$ & 0.93 \\
L-DOPA & $0.56(0.14)$ & $0.47(0.12)$ & $2.79(\mathrm{II})$ & $0.017^{*}$ \\
Rivastigmine & $0.47(0.09)$ & $0.61(0.15)$ & $-2.79(1 \mathrm{l})$ & $0.018^{*}$ \\
\hline
\end{tabular}

Abbreviations: CEA, cortical-evoked activity; LICl, long-interval cortical inhibition activity as measured by CEA pre-drug and post-drug; $t(\mathrm{~d} f)=$ paired $T$-test (degrees of freedom).

Asterisks indicate significant values.

(Vidal and Changeux, 1993) Finally, rivastigmine is known to enhance short afferent inhibition (SAI), which is partly cholinergic mediated and SAI decreases LICI (Udupa et al, 2009), further supporting our finding.

The prefrontal cortex receives glutamatergic inputs from the medial dorsal thalamus (Groenewegen and Uylings, 2000). These thalamocortical glutamatergic projections are modulated by highly expressed presynaptic and postsynaptic cholinergic $\alpha 7-$ nicotinic receptors (Yang et al, 2013). Activation of these receptors increases glutamate release, which results in reduced CI (Parikh et al, 2010). Rivastigmine increases synaptic levels of acetylcholine by inhibiting acetylcholine-esterase, allowing for longer cholinergic receptor activation (Polinsky, 1998). This subtype of the nicotinic receptors is also permeable to calcium, which is important in facilitating NMDA activity and mediating long-term plasticity (LTP) (Yang et al, 2013). In fact, LTP in the motor cortex of healthy participants was enhanced following the administration of rivastigmine (Kuo et al, 2007). Furthermore, activation of the $\alpha 7$ nicotinic receptor has been shown to be essential for cognitive circuits in the DLPFC (Yang et al, 2013). Therefore, based on our observation and prior studies, rivastigmine may have pro-cognitive effects by reducing $\mathrm{CI}$ and, as a corollary, increasing neural plasticity (Ziemann et al, 1998b).

Contrary to our hypothesis, we did not find a difference in LICI for L-DOPA compared to placebo. However, we found that L-DOPA exposure enhanced LICI pre-drug to postdrug, but this was only a trend when corrected for multiple comparisons, which may due to a limited sample size. These findings are in line with animal studies that reported enhanced inhibition in the prefrontal cortex following dopaminergic intervention (Kroner et al, 2007; Towers and Hestrin, 2008). In the prefrontal cortex, dopaminergic axons connect with fast-spiking GABAergic neurons (Sesack et al, 1998). Dopamine increases the firing of these neurons through the activation of $\mathrm{D}_{1}$ receptors (Gorelova et al, 2002). Given that $D_{1}$ receptors are highly expressed in the prefrontal cortex (Gaspar et al, 1995), L-DOPA could have enhanced inhibition through these receptors, however, considering that these dopaminergic effects are downstream and not direct then smaller effects and effect sizes may be due to these indirect influences. Also, these findings support TMS studies that reported increased cortical silent period (CSP) following L-DOPA administration from the motor cortex (Ziemann et al, 1997). These studies are relevant given that CSP similar to LICI is mediated through $\mathrm{GABA}_{\mathrm{B}}$ neurotransmission.

We did not confirm our hypothesis that dextromethorphan would enhance LICI. No previous study assessed the effect of dextromethorphan on LICI. As such our hypothesis was based on a study that reported that dextromethorphan enhanced CI and decreased excitation in the motor cortex (Ziemann et al, 1998a). This study, however, examined the 
effects of dextromethorphan on SICI and not LICI. Although both SICI and LICI are cortical inhibitory circuits, several studies have shown that LICI reduces SICI, suggesting that these two inhibitory paradigms are mediated by different mechanisms (Sanger et al, 2001). Also, dextromethorphan being a non-competitive NMDA receptor antagonist (Church et al, 1985) can reduce CI through activation of NMDA receptors on GABAergic neurons or, enhance inhibition by acting on NMDA receptors on glutamatergic neurons (Olney et al, 1999). Further, dextromethorphan also binds to other non-NMDA sites including, opioid sigmabinding sites (Musacchio et al, 1989), nicotinic receptors (Hernandez et al, 2000), and calcium channels (Netzer et al, 1993) and, therefore, is not a direct NMDA antagonist, potentially explaining our observed effects on LICI. As such further studies are needed to determine the effects of dextromethorphan on LICI.

Clinically, LICI has the potential to serve as a biomarker of schizophrenia and treatment response as several lines of evidence suggest that schizophrenia and other similar disorders are associated with dysfunctional GABAergic inhibitory interneurons (Radhu et al, 2015) (Sun, Farzan et al, 2016). Thus, as a biomarker, LICI has the potential to aid in the early identification of illness, to predict treatment response, and aid in the understanding of the complex neurobiological mechanisms which are involved in this disorder.

This study is limited by a relatively small sample size. However, the sample size was calculated based on previously published literature in the motor cortex. This small sample may have obscured finding smaller effects through agents such as L-DOPA. Another limitation is that we did not measure blood levels of the drugs to time the delivery of post-LICI. However, this limitation was mitigated by delivering post-LICI based on published peak plasma levels. Also, we did not use auditory masking to avoid auditory artifacts as the length of the experiment which would have made it unbearable and uncomfortable for the participants, which in turn would have affected the quality of the recorded data. Finally, this study assessed the impact of a single dose on LICI. These medications are used chronically in clinical settings. Thus, future studies should assess the effects of longer exposure to these medications in healthy individuals as well as patients with neuropsychiatric disorders associated with abnormalities in LICI.

In conclusion, this study confirmed our hypotheses that baclofen-a GABAergic agent-enhanced LICI in the DLPFC while rivastigmine-a cholinergic agent-reduced it. Future studies should assess this modulation in clinical conditions to better understand the pathophysiology underlying these conditions as well the mechanisms that these drugs target in various brain disorders.

\section{FUNDING AND DISCLOSURE}

In the last 3 years, ZJD has received research and equipment in-kind support for an investigator-initiated study through Brainsway and Magventure. He has also served on the advisory board for Sunovion, Hoffmann-La Roche, and Merck, and received speaker support from Eli Lilly. He has received operating grant support from the Ontario Mental Health Foundation (OMHF), the Canadian Institutes of
Health Research (CIHR), the Brain and Behaviour Research Foundation and the Temerty Family and Grant Family and through the Centre for Addiction and Mental Health (CAMH) Foundation and the Campbell Institute. TKR receives research support from Brain Canada, Brain and Behavior Research Foundation, Canadian Foundation for Innovation, CIHR, Ontario Ministry of Health and LongTerm Care, Ontario Ministry of Research and Innovation, the US National Institute of Health $(\mathrm{NIH})$, and the W. Garfield Weston Foundation. BS receives support from the Ontario Mental Health Foundation (OMHF) research studentship and received support from the Ontario Graduate Scholarship as this work contributes to her doctoral dissertation. DMB has received research support from the Canadian Institutes of Health Research (CIHR), National Institute of Health (NIH), Brain Canada and the Temerty Family through the Centre for Addiction and Mental Health (CAMH) Foundation and the Campbell Research Institute. He receives research support and in-kind equipment support for an investigator-initiated study from Brainsway, and he is the site principal investigator for three sponsor-initiated studies for Brainsway. He also receives in-kind equipment support from Magventure for an investigator-initiated study. He receives medication supplies for an investigator-initiated trial from Indivior. RC received research support from the Canadian Institutes of Health Research, Ontario Brain Institute, Medtronic and Merz. TKR, BGP, and RZ declare no conflict of interest.

\section{REFERENCES}

Bestmann S, Krakauer JW (2015). The uses and interpretations of the motor-evoked potential for understanding behaviour. Exp Brain Res 233: 679-689.

Chu J, Wagle-Shukla A, Gunraj C, Lang AE, Chen R (2009). Impaired presynaptic inhibition in the motor cortex in Parkinson disease. Neurology 72: 842-849.

Church J, Lodge D, Berry SC (1985). Differential effects of dextrorphan and levorphanol on the excitation of rat spinal neurons by amino acids. Eur J Pharmacol 111: 185-190.

Croarkin PE, Nakonezny PA, Husain MM, Port JD, Melton T, Kennard BD et al (2014). Evidence for pretreatment LICI deficits among depressed children and adolescents with nonresponse to fluoxetine. Brain Stimul 7: 243-251.

Daskalakis ZJ, Farzan F, Barr MS, Maller JJ, Chen R, Fitzgerald PB (2008). Long-interval cortical inhibition from the dorsolateral prefrontal cortex: a TMS-EEG study. Neuropsychopharmacology 33: 2860-2869.

Faigle JW, Keberle H (1972). The chemistry and kinetics of Lioresal. Postgrad Med J 48(Suppl 5): 9-13.

Farzan F, Barr MS, Levinson AJ, Chen R, Wong W, Fitzgerald PB et al (2010). Reliability of long-interval cortical inhibition in healthy human subjects: a TMS-EEG study. J Neurophysiol 104: 1339-1346.

Fuster J (2008). The Prefrontal Cortex, 4th edn. Academic Press: Boston, MA, USA.

Gaspar P, Bloch B, Le Moine C (1995). D1 and D2 receptor gene expression in the rat frontal cortex: cellular localization in different classes of efferent neurons. Eur Neurosci 7: 1050-1063.

Gorelova N, Seamans JK, Yang CR (2002). Mechanisms of dopamine activation of fast-spiking interneurons that exert inhibition in rat prefrontal cortex. $J$ Neurophysiol 88: 3150-3166. 
Goto Y, Yang CR, Otani S (2010). Functional and dysfunctional synaptic plasticity in prefrontal cortex: roles in psychiatric disorders. Biol Psychiatry 67: 199-207.

Groenewegen HJ, Uylings HB (2000). The prefrontal cortex and the integration of sensory, limbic and autonomic information. Prog Brain Res 126: 3-28.

Harsing LG Jr, Zigmond MJ (1997). Influence of dopamine on GABA release in striatum: evidence for D1-D2 interactions and non-synaptic influences. Neuroscience 77: 419-429.

Heaney CF, Kinney JW (2016). Role of GABA(B) receptors in learning and memory and neurological disorders. Neurosci Biobehav Rev 63: 1-28.

Hernandez SC, Bertolino M, Xiao Y, Pringle KE, Caruso FS, Kellar KJ (2000). Dextromethorphan and its metabolite dextrorphan block alpha3beta4 neuronal nicotinic receptors. J pharmacol Exp Ther 293: 962-967.

Kaster TS, de Jesus D, Radhu N, Farzan F, Blumberger DM, Rajji TK et al (2015). Clozapine potentiation of GABA mediated cortical inhibition in treatment resistant schizophrenia. Schizophr Res 165: 157-162.

Kaufman LD, Pratt J, Levine B, Black SE (2010). Antisaccades: a probe into the dorsolateral prefrontal cortex in Alzheimer's disease. A critical review. J Alzheimer's Dis 19: 781-793.

Ko JH, Antonelli F, Monchi O, Ray N, Rusjan P, Houle S et al (2013). Prefrontal dopaminergic receptor abnormalities and executive functions in Parkinson's disease. Hum Brain Mapp 34: $1591-1604$

Koenigs M, Grafman J (2009). The functional neuroanatomy of depression: distinct roles for ventromedial and dorsolateral prefrontal cortex. Behav Brain Res 201: 239-243.

Korchounov A, Ziemann U (2011). Neuromodulatory neurotransmitters influence LTP-like plasticity in human cortex: a pharmacoTMS study. Neuropsychopharmacology 36: 1894-1902.

Kroner S, Krimer LS, Lewis DA, Barrionuevo G (2007). Dopamine increases inhibition in the monkey dorsolateral prefrontal cortex through cell type-specific modulation of interneurons. Cereb Cortex 17: 1020-1032.

Kuo MF, Grosch J, Fregni F, Paulus W, Nitsche MA (2007). Focusing effect of acetylcholine on neuroplasticity in the human motor cortex. J Neurosci 27: 14442-14447.

Langguth B, Bauer E, Feix S, Landgrebe M, Binder H, Sand P et al (2007). Modulation of human motor cortex excitability by the cholinesterase inhibitor rivastigmine. Neurosci Lett 415: 40-44.

Mann-Metzer P, Yarom Y (2002). Pre- and postsynaptic inhibition mediated by $\mathrm{GABA}(\mathrm{B})$ receptors in cerebellar inhibitory interneurons. J Neurophysiol 87: 183-190.

McCormick DA (1989). GABA as an inhibitory neurotransmitter in human cerebral cortex. J Neurophysiol 62: 1018-1027.

McDonnell MN, Orekhov Y, Ziemann U (2006). The role of GABA (B) receptors in intracortical inhibition in the human motor cortex. Exp Brain Res 173: 86-93.

Musacchio JM, Klein M, Canoll PD (1989). Dextromethorphan and sigma ligands: common sites but diverse effects. Life Sci 45: $1721-1732$.

Naim-Feil J, Bradshaw JL, Rogasch NC, Daskalakis ZJ, Sheppard DM, Lubman DI et al (2015). Cortical inhibition within motor and frontal regions in alcohol dependence post-detoxification: a pilot TMS-EEG study. World J Biol Psychiatry 17: 547-556.

Netzer R, Pflimlin P, Trube G (1993). Dextromethorphan blocks $\mathrm{N}$-methyl-D-aspartate-induced currents and voltage-operated inward currents in cultured cortical neurons. Eur J Pharmacol 238: 209-216.

Olney JW, Newcomer JW, Farber NB (1999). NMDA receptor hypofunction model of schizophrenia. J Psychiatr Res 33: 523-533.

Parikh V, Ji J, Decker MW, Sarter M (2010). Prefrontal beta2 subunit-containing and alpha7 nicotinic acetylcholine receptors differentially control glutamatergic and cholinergic signaling. J Neurosci 30: 3518-3530.
Paulus W, Classen J, Cohen LG, Large CH, Di Lazzaro V, Nitsche M et al (2008). State of the art: pharmacologic effects on cortical excitability measures tested by transcranial magnetic stimulation. Brain Stimul 1: 151-163.

Pierantozzi M, Marciani MG, Palmieri MG, Brusa L, Galati S, Caramia MD et al (2004). Effect of Vigabatrin on motor responses to transcranial magnetic stimulation: an effective tool to investigate in vivo GABAergic cortical inhibition in humans. Brain Res 1028: 1-8.

Polinsky RJ (1998). Clinical pharmacology of rivastigmine: a new-generation acetylcholinesterase inhibitor for the treatment of Alzheimer's disease. Clin Ther 20: 634-647.

Porter JT, Nieves D (2004). Presynaptic GABAB receptors modulate thalamic excitation of inhibitory and excitatory neurons in the mouse barrel cortex. J Neurophysiol 92: 2762-2770.

Premoli I, Rivolta D, Espenhahn S, Castellanos N, Belardinelli P, Ziemann U et al (2014). Characterization of GABAB-receptor mediated neurotransmission in the human cortex by paired-pulse TMS-EEG. NeuroImage 103: 152-162.

Priori A, Berardelli A, Inghilleri $\mathrm{M}$, Accornero $\mathrm{N}$, Manfredi $\mathrm{M}$ (1994). Motor cortical inhibition and the dopaminergic system. Pharmacological changes in the silent period after transcranial brain stimulation in normal subjects, patients with Parkinson's disease and drug-induced parkinsonism. Brain 117( $\mathrm{Pt} 2)$ : 317-323.

Radhu N, Garcia Dominguez L, Farzan F, Richter MA, Semeralul MO, Chen $\mathrm{R}$ et al (2015). Evidence for inhibitory deficits in the prefrontal cortex in schizophrenia. Brain 138(Pt 2): 483-497.

Rogasch NC, Daskalakis ZJ, Fitzgerald PB (2015). Cortical inhibition of distinct mechanisms in the dorsolateral prefrontal cortex is related to working memory performance: a TMSEEG study. Cortex 64: 68-77.

Rossi S, Hallett M, Rossini PM, Pascual-Leone A (2009). Safety, ethical considerations, and application guidelines for the use of transcranial magnetic stimulation in clinical practice and research. Clin Neurophysiol 120: 2008-2039.

Rusjan PM, Barr MS, Farzan F, Arenovich T, Maller JJ, Fitzgerald $\mathrm{PB}$ et al (2010). Optimal transcranial magnetic stimulation coil placement for targeting the dorsolateral prefrontal cortex using novel magnetic resonance image-guided neuronavigation. Hum Brain Mapp 31: 1643-1652.

Sanger TD, Garg RR, Chen R (2001). Interactions between two different inhibitory systems in the human motor cortex. J Physiol 530(Pt 2): 307-317.

Sederberg PB, Schulze-Bonhage A, Madsen JR, Bromfield EB, McCarthy DC, Brandt A et al (2007). Hippocampal and neocortical gamma oscillations predict memory formation in humans. Cereb Cortex 17: 1190-1196.

Sesack SR, Hawrylak VA, Melchitzky DS, Lewis DA (1998). Dopamine innervation of a subclass of local circuit neurons in monkey prefrontal cortex: ultrastructural analysis of tyrosine hydroxylase and parvalbumin immunoreactive structures. Cereb Cortex 8: 614-622.

Sun Y, Farzan F, Mulsant BH, Rajji TK, Fitzgerald PB, Barr MS et al (2016). Indicators for remission of suicidal ideation following magnetic seizure therapy in patients with treatment-resistant depression. JAMA Psychiatry 73: 337-345.

Towers SK, Hestrin S (2008). D1-like dopamine receptor activation modulates GABAergic inhibition but not electrical coupling between neocortical fast-spiking interneurons. J Neurosci 28: $2633-2641$.

Udupa K, Ni Z, Gunraj C, Chen R (2009). Interactions between short latency afferent inhibition and long interval intracortical inhibition. Exp Brain Res 199: 177-183.

Valls-Sole J, Pascual-Leone A, Wassermann EM, Hallett M (1992). Human motor evoked responses to paired transcranial magnetic stimuli. Electroencephalogr Clin Neurophysiol 85: 355-364. 
Vidal C, Changeux JP (1993). Nicotinic and muscarinic modulations of excitatory synaptic transmission in the rat prefrontal cortex in vitro. Neuroscience 56: 23-32.

Werhahn KJ, Kunesch E, Noachtar S, Benecke R, Classen J (1999). Differential effects on motorcortical inhibition induced by blockade of GABA uptake in humans. J Physiol 517(Pt 2): 591-597.

Yang Y, Paspalas CD, Jin LE, Picciotto MR, Arnsten AF, Wang M (2013). Nicotinic alpha7 receptors enhance NMDA cognitive circuits in dorsolateral prefrontal cortex. Proc Natl Acad Sci USA 110: 12078-12083.

Zhang L, Warren RA (2002). Muscarinic and nicotinic presynaptic modulation of EPSCs in the nucleus accumbens during postnatal development. J Neurophysiol 88: 3315-3330.
Ziemann U, Chen R, Cohen LG, Hallett M (1998a). Dextromethorphan decreases the excitability of the human motor cortex. Neurology 51: 1320-1324.

Ziemann U, Hallett M, Cohen LG (1998b). Mechanisms of deafferentation-induced plasticity in human motor cortex. J Neurosci 18: 7000-7007.

Ziemann U, Reis J, Schwenkreis P, Rosanova M, Strafella A, Badawy $\mathrm{R}$ et al (2015). TMS and drugs revisited 2014. Clin Neurophysiol 126: 1847-1868.

Ziemann U, Tergau F, Bruns D, Baudewig J, Paulus W (1997). Changes in human motor cortex excitability induced by dopaminergic and anti-dopaminergic drugs. Electroencephalogr Clin Neurophysiol 105: 430-437. 